Research Article

\title{
Production of Acetaldehyde via Oxidative Dehydrogenation of Ethanol over $\mathrm{AgLi} / \mathrm{SiO}_{2}$ Catalysts
}

\author{
Narawich Mukda, Chaowat Autthanit, Piyasan Praserthdam, Bunjerd Jongsomjit* \\ ${ }^{1}$ Center of Excellence on Catalysis and Catalytic Reaction Engineering, Department of Chemical \\ Engineering, Faculty of Engineering, Chulalongkorn University, Bangkok 10330, Thailand
}

Received: 15th August 2020; Revised: 17th September 2020; Accepted: $18^{\text {th }}$ September 2020; Available online: 19th September 2020; Published regularly: December 2020

\begin{abstract}
Three $\mathrm{AgLi} / \mathrm{SiO}_{2}$ catalysts containing different types of silica supports [small particle size (SPS), medium particle size (MPS), and large particle size (LPS)] were prepared by incipient wetness coimpregnation techniques and tested in oxidative dehydrogenation of ethanol into acetaldehyde. The catalysts were characterized and evaluated by various characterization techniques (e.g. XRD, $\mathrm{N}_{2}$ physisorption, SEM-EDX, UV-Visible spectroscopy, $\mathrm{H}_{2}$-TPR, and $\mathrm{CO}_{2}$-TPD). This study reveals that the catalyst with the best performance is $\mathrm{AgLi} / \mathrm{SiO}_{2}$ - $\mathrm{LPS}$ with a yield in acetaldehyde of $76.8 \%$ at $300{ }^{\circ} \mathrm{C}$. The results obtained with the tested catalysts are discussed, and the reasons of performance improvement caused by the presence of the dispersion of active components, the interaction between active components and silica supports, the textural properties of catalysts and reducibility, are raised. Besides, the cooperation of redox properties $\left(\mathrm{Ag}_{\mathrm{n}}{ }^{{ }^{+}}\right.$cluster and $\left.\mathrm{Ag}{ }^{0}\right)$ and weak basic density played a pivotal role in promoting the formation of acetaldehyde from ethanol oxidative dehydrogenation. Copyright (C) 2020 BCREC Group. All rights reserved
\end{abstract}

Keywords: Oxidative dehydrogenation of ethanol; Silver-lithium; Silica; Acetaldehyde

How to Cite: Mukda, N., Autthanit, C., Praserthdam, P., Jongsomjit, B. (2020). Production of Acetaldehyde via Oxidative Dehydrogenation of Ethanol over $\mathrm{AgLi} / \mathrm{SiO}_{2}$ Catalysts. Bulletin of Chemical Reaction Engineering \& Catalysis, 15(3), 714-725 (doi:10.9767/bcrec.15.3.8702.714-725)

Permalink/DOI: https://doi.org/10.9767/bcrec.15.3.8702.714-725

\section{Introduction}

Ethanol is possibly the most promising biomass-derived chemical to supplant traditional fossil feedstocks [1,2]. Because of the incentivedriven and government-mandated increase in bioethanol output, it is now becoming economical within the circular economy to use ethanol as base for value chains to chemicals, such as acetaldehyde, ethylene, diethyl ether, acetic

\footnotetext{
* Corresponding Author.

E-mail: bunjerd.j@chula.ac.th (B. Jongsomjit)

Telp: +662-218-6874, Fax: 662-218-6877
}

acid, ethyl acetate, butadiene, and others [3-6]. Nowadays, acetaldehyde is generally used in petrochemical industry for the preparation of pyridines derivatives, acetic acid, vinyl acetate, and useful resin. There are different reaction routes to produce acetaldehyde in industries including: (1) partial oxidation of ethane using $\mathrm{PdCl}_{2} / \mathrm{CuCl}_{2}$ catalyst system (Wacker process), which is not only an expensive catalyst, but also uses high temperature for operation [7]; (2) hydration of acetylene, which has spent mercury $(\mathrm{Hg})$ to form mercuric complex that is toxic material for the environmental concern [8]; and (3) oxidation of ethylene from petroleum and natu- 
ral gas [9]. However, such processes have so far been ineffective due to rapid catalyst deactivation, spurring continuing research in this area. Hence, theimportance of acetaldehyde as an organic intermediate is now gradually decreasing, because new reaction processes for acetaldehyde have been developed [10].It is worth noting that oxidative dehydrogenation of ethanol to produce acetaldehyde is a feasible process because of the low intrinsic chemical reactivity of the ethanol without any equilibriumlimited reactions, as well as high acetaldehyde yield can be obtained under mild reaction conditions [11,13]. Consequently, in order to obtain the desired products from ethanol, effective catalysts must be developed and this becomes the most important factor of this research.

Heterogeneous catalytic systems are kinetically controlled by surface accessibility and metal-support interactions. Therefore, most previous published work on oxidation reactions using heterogeneous catalysts have focused mainly on active metal catalysts, such as $\mathrm{Cu}$, $\mathrm{Ni}, \mathrm{Pd}, \mathrm{Pt}$, and $\mathrm{Au}$ [14-16]. These metal promoters primarily enhance the dehydrogenation activity and modify the ratio of acid/base sites on the catalyst surface. However, these metals are too expensive to use at an industrial scale. Development of novel pathway to create highly active site, stable, and industrially attractive catalysts is of great current interest.Ag-based catalysts are promising materials for acetaldehyde production from ethanol due to high activity, high selectivity and low cost in comparison with other supported catalysts based on noble metals $[17,18]$. In our previous study [19], we investigated the $\mathrm{Ag} / \mathrm{Li}$ onto $\mathrm{TiO}_{2}$ catalyst system by evaluating the use of several types of $\mathrm{TiO}_{2}$ supports (e.g. anatase, rutile, and mixed phases) found to significantly influence both conversion and selectivity in the ethanol dehydrogenation reaction. In addition, Janlamool et al. [20] reported that a $\mathrm{Ag} / \mathrm{Li}$ formulation anchored on $\mathrm{Al}_{2} \mathrm{O}_{3}$ (mixed $\gamma$ - and $x$-crystalline phases) presents high selectivity to acetaldehyde. The impressive yield of acetaldehyde was obtained at the suitable reaction condition. In fact, these $\mathrm{Ag}$ and $\mathrm{Li}$ based catalysts can be further modified and used in other catalytic reactions including oxidative dehydrogenation of alcohols into corresponding carbonyl compounds.

A wide spread of catalytic systems including $\mathrm{Al}_{2} \mathrm{O}_{3}, \mathrm{TiO}_{2}, \mathrm{SiO}_{2}$, clay, zeolite-based catalysts, and others for effective conversion of ethanol to higher valve products was investigated [17,2123]. Across various catalysts investigated, balancing/controlling the available acid-base sites on the catalyst surface has been recognized as the key design metric for controlling the selectivity of desire products. For instance, in $\mathrm{SiO}_{2}$ supported metal oxide catalysts, weak basic sites were reportedly responsible for the rate limiting step (RLS) of ethanol dehydrogenation to acetaldehyde, while strong basic sites promoted the aldol condensation of acetaldehyde to form crotonaldehyde [24,25]. In addition, the spherical silica particle (SSP) is one type of silica that has shown appropriate properties due to its great support such as their pore size distribution, thermal stability, and high surface area [26]. However, it is still highly challenging to develop low cost catalysts due to the high cost of precious metals. It was reported that $\mathrm{Ag}$-based $\mathrm{SiO}_{2}$ catalysts displayed some remarkable ability in oxidative dehydrogenation of ethanol into acetaldehyde $[17,27]$. Therefore, we can infer from the conclusion that $\mathrm{SiO}_{2}$ is very suitable as the support for Ag-based dehydrogenation catalysts. However, to our best knowledge, there is no available literature concerning the AgLi doped with different types of $\mathrm{SiO}_{2}$ that can play in catalytic ethanol oxidative dehydrogenation.

In the present work, we aim to further develop the $\mathrm{AgLi} / \mathrm{SiO}_{2}$ catalysts having different types of silica supports (SPS, MPS, and LPS) for enhancing the catalytic performance in oxidative dehydrogenation of ethanol to acetaldehyde. Detailed characterizations (by XRD, $\mathrm{N}_{2}$ physisorption, SEM-EDX, UV-visible, $\mathrm{H}_{2}$-TPR, and $\mathrm{CO}_{2}$-TPD techniques) have been carried out in order to obtain insight into structural features, chemical oxidation state of silver, types of silver species and the overall effect on the catalytic performance. The choice of catalysts was made on the basis of their oxidationreduction and basic properties, as well as the catalytic properties demonstrated in ethanol oxidative dehydrogenation reaction.

\section{Materials and Method}

\subsection{Materials}

The chemicals used for preparation of the catalysts were tetraethyl orthosilicate (TEOS) (98\%, Aldrich), cetyltrimethylammonium bromide (CTAB) (Aldrich), ammonia 30\% (Panreac), silver(I) nitrate 99 wt\% (Aldrich), and lithium(I) nitrate $98 \mathrm{wt} \%$ (Aldrich). The commercial silica supports (medium particle size and large particle size) were purchased from Sigma-Aldrich. Gases employed were He (99.99\%, Air Liquide), $\mathrm{H}_{2}$ (99.999\%, Air Liquide), $\mathrm{N}_{2}$ (99.9999\%, Air Liquide) and syn- 
thetic air (99.99\%, Air Liquide). The solutions used in this study were prepared with deionized water.

\subsection{Synthesis of Spherical Silica Particle Sup- port}

The spherical silica particle support was prepared by sol-gel method as reported by Chanchuey et al. [26] and Fuchigami et al. [28]. The synthesized gel was prepared by mixing the composition of 1 TEOS : 0.3 CTAB : $11 \mathrm{NH}_{3}$ : 58 ethanol : $144 \mathrm{H}_{2} \mathrm{O}$ (molar ratio). Then, the mixture was mixed and stirred at room temperature for $2 \mathrm{~h}$. After that, the white precipitate was separated from solvent by centrifuge. Then, the sample was dried at $110{ }^{\circ} \mathrm{C}$ overnight and calcined in air at $550{ }^{\circ} \mathrm{C}$ for $6 \mathrm{~h}$. Finally, the spherical silica particle was obtained in form of white powder.

\subsection{Preparation of Silver and Lithium Loaded} on Spherical Silica Particle and Commercial Silica Supports

The $\mathrm{AgLi}-\mathrm{SiO}_{2}$ catalysts were prepared by the incipient wetness co-impregnation method. Silver(I) nitrate and lithium(I) nitrate were mixed with an optimum composition to obtain $4.7 \mathrm{wt} \%$ of $\mathrm{Ag}$ and $0.7 \mathrm{wt} \%$ of $\mathrm{Li}$ on the spherical silica particle and two commercial silica supports. Then, the catalysts were dried at 110 ${ }^{\circ} \mathrm{C}$ overnight and calcined in the air at $400{ }^{\circ} \mathrm{C}$ for $4 \mathrm{~h}$ with heating rate of $10^{\circ} \mathrm{C} \cdot \mathrm{min}^{-1}$.

The nomenclature of all different catalysts, decided based on their silica particle size, is listed as follows: (1) spherical silica particle support $(0.6 \mu \mathrm{m})$ was denoted as small particle size (SPS); (2) first commercial silica support (2 $\mu \mathrm{m})$ was denoted as medium particle size (MPS); and (3) second commercial silica support $(2.8 \mu \mathrm{m})$ was denoted as large particle size (LPS).

\subsection{Characterization}

The crystalline phases were identified by using a SIEMENS D-5000 X-ray diffractometer (XRD) with $\mathrm{Cu}-\mathrm{Ka}(\lambda=1.54439 \AA)$. The XRD patterns were recorded over the $2 \theta$ between $20^{\circ}$ and $80^{\circ}$ with resolution of $0.04^{\circ}$. The adsorption-desorption isotherms of nitrogen at $-196{ }^{\circ} \mathrm{C}$ were obtained from gas sorption techniques (Micromeritics ASAP 2020). The specific surface areas were determined from adsorption values for relative pressure $\left(P / P_{0}\right)$ by using the BET method. The total pore volume was estimated from the total amount of adsorbed nitrogen by using the BJH method.
With respect to scanning electron microscopy (SEM) and energy dispersive X-ray spectroscopy (EDX), The simple morphologies and elemental distribution were examined by SEM using a JEOL JSM-5800LV model and EDX using Link Isis series 300 program operated at $100 \mathrm{kV}$. For the Inductively Coupled Plasma (ICP), a quantity of elemental composition in the catalysts was measured by Perkin Elmer OPTIMA2000TM instrument. Before testing, the catalysts must be converted to liquid form before testing by dissolving the catalysts in a solvent (typically acid) to produce a solution.

For the UV-visible spectroscopy (UV-vis), the optical absorption of the catalysts was recorded on a Perkin Elmer Lambda-650 instrument. The catalyst $(\sim 200-300 \mathrm{mg})$ was loaded into a quartz cell with $1.0 \mathrm{~cm}$ path length. The measurements were carried out at room temperature in the wavelength between 200 to $800 \mathrm{~nm}$ at a step of $0.5 \mathrm{~nm}$ with a band width of $2 \mathrm{~nm}$. $\mathrm{BaSO}_{4}$ was used as a reference sample to measure the baseline spectrum.

In temperature-programmed reduction $\left(\mathrm{H}_{2}\right.$-TPR), The reduction behavior of $\mathrm{H}_{2}$ was analyzed using BELCAT-A instruments (BEL Japan, Inc.). Before the measurements, the catalysts $(\sim 100 \mathrm{mg})$ were pretreated at $250{ }^{\circ} \mathrm{C}$ under nitrogen flow for $1 \mathrm{~h}$. The reduction profile was operated at temperature ramping to $500{ }^{\circ} \mathrm{C}$ with $10{ }^{\circ} \mathrm{C} / \mathrm{min}$ during flowing of $10 \%$ $\mathrm{H}_{2}$ in an $\mathrm{Ar}$ stream, and the concentration of $\mathrm{H}_{2}$ was monitored by a thermal conductivity detector (TCD) and mass spectrometer (Bell Mass, BEL, Japan).

In the case of carbon dioxide temperatureprogrammed desorption $\left(\mathrm{CO}_{2}\right.$-TPD), the basicity properties of all catalysts were determined by temperature programmed desorption of carbon dioxide $\left(\mathrm{CO}_{2}\right.$-TPD) using a Micromeritics Chemisorp 2750 with a computer. First, $\sim 100$ $\mathrm{mg}$ of the catalyst was pretreated at $400{ }^{\circ} \mathrm{C}$ with flowing of helium (30 mL.min $\left.{ }^{-1}\right)$ for $1 \mathrm{~h}$. Catalysts were then cooled to $30{ }^{\circ} \mathrm{C}$ and saturated with $50 \mathrm{~mL} \cdot \mathrm{min}^{-1} \mathrm{CO}_{2}$ (basic sites) for 60 min. After saturation, the physisorbed $\mathrm{CO}_{2}$ was desorbed in a He flowing at flow rate of 35 $\mathrm{cm}^{3} / \mathrm{min}$ for $30 \mathrm{~min}$. Then, the temperature was carried out from $30{ }^{\circ} \mathrm{C}$ to $500{ }^{\circ} \mathrm{C}$ with heating rate of $10{ }^{\circ} \mathrm{C} \cdot \mathrm{min}^{-1}$. The amount of $\mathrm{CO}_{2}$ in effluent gas was analyzed by thermal conductivity detector (TCD) as a function of desorbed temperature.

\subsection{Catalytic Reaction}

The procedure used in carrying out the reactions was similar to those described by our pre- 
vious work $[19,29]$. The catalytic activity was achieved under atmospheric pressure in a fixed-bed continuous flow micro-reactor $(7 \mathrm{~mm}$ in diameter and $330 \mathrm{~mm}$ in length, made from a borosilicate glass tube). The reaction temperature was measured with an interior placed thermocouple in direct contact with the catalyst bed. The catalyst $(0.05 \mathrm{~g})$ was charged onto packed quartz wool $(0.01 \mathrm{~g})$ in the middle of microreactor, which is located in the electric furnace. The temperature of the catalyst was measured with a thermocouple reaching the top of the catalyst bed. In order to eliminate the impurity on surface of catalyst prior to reaction, the catalyst was pretreated in $\mathrm{N}_{2}$ with $50 \mathrm{~mL} / \mathrm{min}$ at $200^{\circ} \mathrm{C}$ for $1 \mathrm{~h}$. After finished the preheat step, the catalyst sample was reduced in the hydrogen atmosphere at $300{ }^{\circ} \mathrm{C}$ for $1 \mathrm{~h}$ before the reaction. The liquid ethanol was fed into the vaporizer at $150{ }^{\circ} \mathrm{C}$ and ethanol flow rate was controlled by a single syringe pump at $1.45 \mathrm{~mL} / \mathrm{h}$ [i.e. the weight hourly space velocity $($ WHSV $)=22.9\left(\right.$ g ethanol.gcat $\left.\left.^{-1}\right) \cdot \mathrm{h}^{-1}\right]$. Furthermore, we carried out the oxidative dehydrogenation of ethanol from $200{ }^{\circ} \mathrm{C}$ to $400{ }^{\circ} \mathrm{C}$. The feed mixture contained of ethanol/oxygen (air) molar ratio of $2 / 1$. Thus, the flow rate of $\mathrm{N}_{2}$ carrier gas was decreased to $17.8 \mathrm{~mL} / \mathrm{min}$ and air was presented at the flow rate of 46 $\mathrm{mL} / \mathrm{min}$. Finally, ethanol conversion and product selectivity were collected at steady state. The effluent gas was continuously analyzed by gas chromatograph with flame ionization detector (FID) and thermal conductivity detector (TCD). While the reaction test (Scheme 1) was operated, the results were repeatedly recorded at least 3 times for each temperature.

\section{Results and Discussion}

3.1 Catalyst Characterization

The XRD patterns of all catalysts are shown in Figure 1. It can be seen that the diffraction peaks of bare $\mathrm{SiO}_{2}$ supports exhibited only

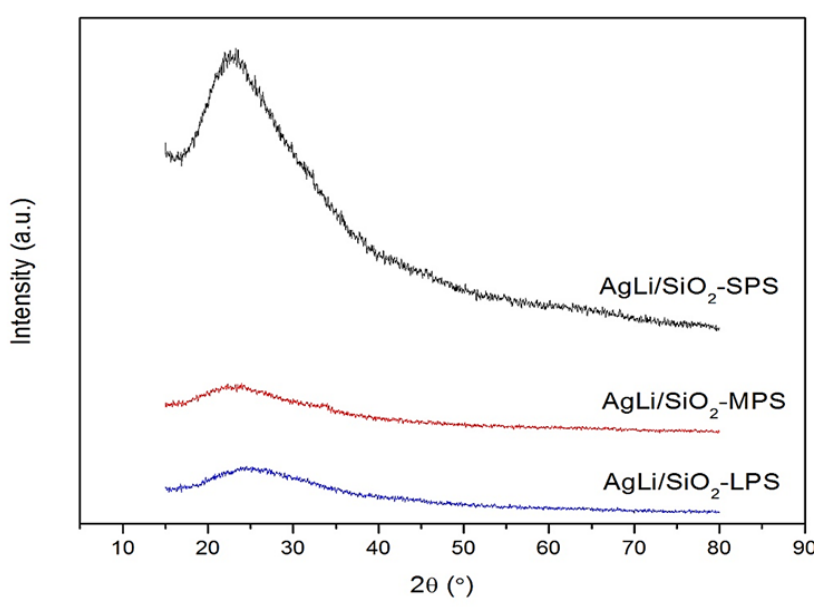

Figure 1. XRD patterns of all catalysts

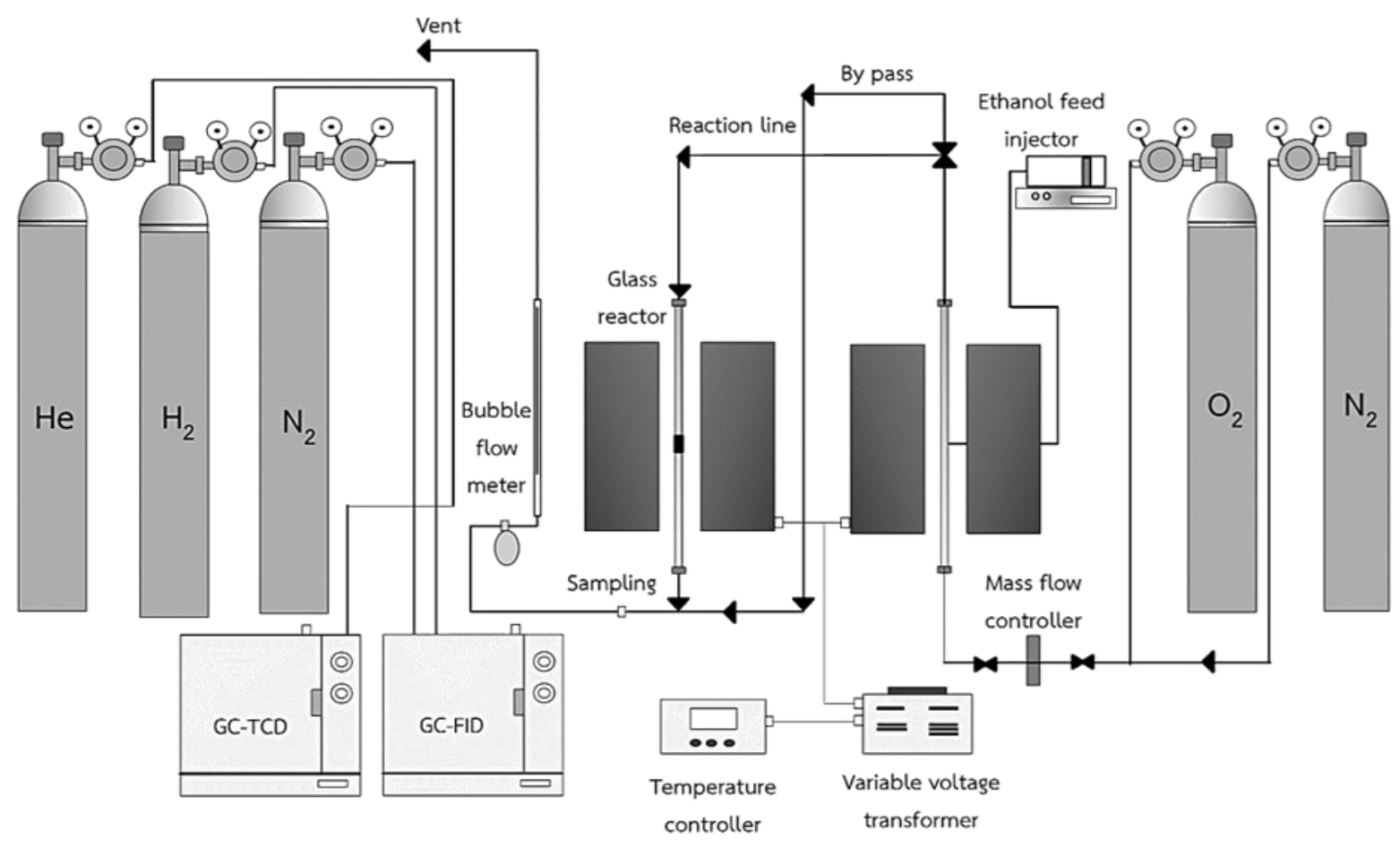

Scheme 1. Flow diagram of ethanol oxidative dehydrogenation system 
amorphous form resulted in strong broad hump peak observation between $15-30^{\circ}$ at $2 \theta$ values (Figure S1 Supplementary). Zhang et al. [30] also recorded one broadened XRD peak for amorphous $\mathrm{SiO}_{2}$ centered at a $2 \theta$ value close to our measurement. For $\mathrm{AgLi} / \mathrm{SiO}_{2}$-SPS, $\mathrm{AgLi} / \mathrm{SiO}_{2}-\mathrm{MPS}$, and $\mathrm{AgLi} / \mathrm{SiO}_{2}-\mathrm{LPS}$ catalysts, no diffraction peaks of metal oxide ( $\mathrm{Ag}$ and $\mathrm{Li}$ ) crystalline phase were observed. It was due to the minor amounts of metal oxide nanoparticles possess a good dispersion on the $\mathrm{SiO}_{2}$ supports with very small size. The metals particles were too small to be detected by XRD.

The surface areas, pore volume and pore diameter of all catalysts were determined from the $\mathrm{N}_{2}$ physisorption as listed in Table 1 . It indicated that $\mathrm{SiO}_{2}$-SPS $\left(1,023 \mathrm{~m}^{2} / \mathrm{g}\right)$ exhibited the largest specific surface area among all supports $\left(\mathrm{SiO}_{2}\right.$-MPS $=521 \mathrm{~m}^{2} / \mathrm{g}$ and $\mathrm{SiO}_{2}$-LPS $=$ $655 \mathrm{~m}^{2} / \mathrm{g}$ ). After the incorporation of silverlithium on all different $\mathrm{SiO}_{2}$ supports, the BET surface area decreases in the following sequence: $\mathrm{AgLi} / \mathrm{SiO}_{2}-\mathrm{SPS}\left(675 \mathrm{~m}^{2} / \mathrm{g}\right)>\mathrm{AgLi} / \mathrm{SiO}_{2}$ MPS $\left(423 \mathrm{~m}^{2} / \mathrm{g}\right)>\operatorname{AgLi} / \mathrm{SiO}_{2}$-LPS $\left(290 \mathrm{~m}^{2} / \mathrm{g}\right)$.

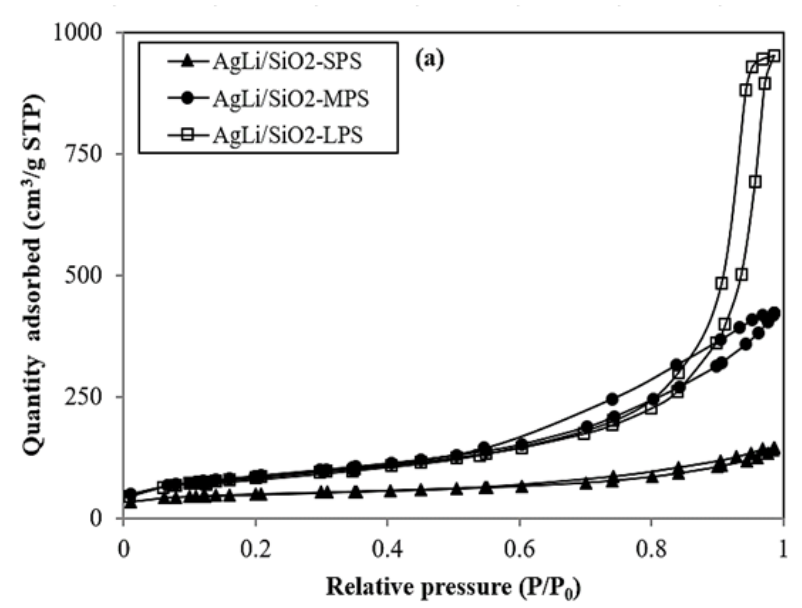

The conspicuous reduction in the surface area of the $\mathrm{SiO}_{2}$ supports on Ag-Li impregnation, suggests silver-lithium crystallites are blocking or are present in the pores of the supports. Moreover, the average pore diameter was ranged from 2.1 to $15.0 \mathrm{~nm}$ within the boundary of mesoporous values. The pore structures of all catalysts presented as the $\mathrm{N}_{2}$ adsorptiondesorption isotherms are shown in Figure 2(a). All catalysts display the hysteresis loop at relative pressure $\left(P / P_{0}>0.4\right)$ indicating that they are mesoporous structure corresponding to Type IV (IUPAC). However, it can be observed that for $\mathrm{AgLi} / \mathrm{SiO}_{2}$-LPS, the hysteresis loop is much higher indicating larger mesoporosity character than $\mathrm{AgLi} / \mathrm{SiO}_{2}-\mathrm{SPS}$ and $\mathrm{AgLi} / \mathrm{SiO}_{2}$ MPS catalysts. The change in pore structures is confirmed by a plot of pore volume and pore diameter as seen in Figure 2(b). It can be also observed that the pore diameters of all catalysts are ranged between 2 to $50 \mathrm{~nm}$ indicating the mesoporous material.

The SEM images of $\mathrm{AgLi} / \mathrm{SiO}_{2}$-SPS, $\mathrm{AgLi} / \mathrm{SiO}_{2}$-MPS and $\mathrm{AgLi} / \mathrm{SiO}_{2}$-LPS catalysts

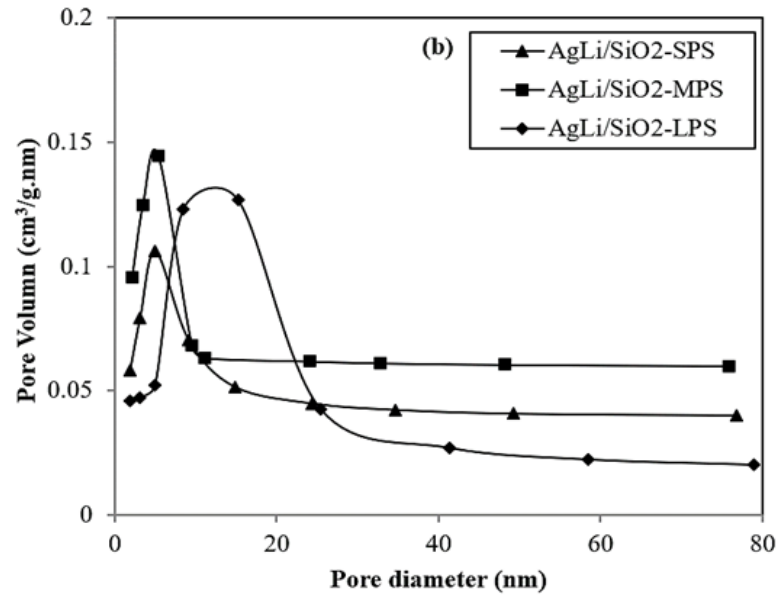

Figure 2. (a) Nitrogen adsorption/desorption isotherms of all catalysts; (b) BJH pore size distribution of all catalysts.

Table 1. Properties of all catalysts

\begin{tabular}{|c|c|c|c|c|c|c|c|c|c|c|c|c|c|}
\hline \multirow[b]{2}{*}{ Catalysts } & \multirow{2}{*}{$\begin{array}{c}\text { BET } \\
\text { surface } \\
\text { area }^{\mathrm{a}} \\
\left(\mathrm{m}^{2} / \mathrm{g}\right)\end{array}$} & \multirow{2}{*}{$\begin{array}{c}\text { Pore } \\
\text { volume } \\
\left(\mathrm{cm}^{3} / \mathrm{g}\right)\end{array}$} & \multirow{2}{*}{$\begin{array}{c}\text { Pore } \\
\text { diameter } \\
\text { b } \\
(n m)\end{array}$} & \multicolumn{3}{|c|}{$\begin{array}{l}\text { Number of basic site ( } \mu \text { mole } \\
\qquad \mathrm{CO}_{2} / \mathrm{g} \text { cat) }\end{array}$} & $\begin{array}{c}\text { Basic } \\
\text { density } \\
(\mu \mathrm{mole} / \\
\left.\mathrm{m}^{2}\right)\end{array}$ & \multicolumn{3}{|c|}{$\begin{array}{c}\text { Amount of element } \\
\text { on surface }{ }^{d}(w t \%)\end{array}$} & \multicolumn{3}{|c|}{ 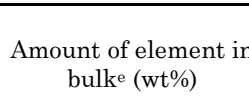 } \\
\hline & & & & $\begin{array}{c}\text { Weak } \\
\text { basic } \\
\text { site }\end{array}$ & $\begin{array}{c}\text { Medium- } \\
\text { to- } \\
\text { Strong } \\
\text { basic site }\end{array}$ & $\begin{array}{l}\text { Total } \\
\text { basic } \\
\text { sites }\end{array}$ & $\begin{array}{c}\text { Weak } \\
\text { basic site }\end{array}$ & $\mathrm{O}_{2}$ & $\mathrm{Si}$ & $\mathrm{Ag}$ & $\mathrm{Si}$ & $\mathrm{Ag}$ & $\mathrm{Li}$ \\
\hline $\mathrm{AgLi} / \mathrm{SiO}_{2}-\mathrm{SPS}$ & 675 & 0.84 & 2.1 & 416.5 & 362.2 & 778.7 & 0.62 & 42.5 & 52.0 & 5.5 & 53.2 & 4.6 & 0.5 \\
\hline $\mathrm{AgLi} / \mathrm{SiO}_{2}-\mathrm{MPS}$ & 423 & 1.54 & 11.0 & 443.0 & 432.3 & 875.3 & 1.05 & 51.6 & 43.1 & 5.3 & 45.7 & 4.3 & 0.5 \\
\hline $\mathrm{AgLi} / \mathrm{SiO}_{2}-\mathrm{LPS}$ & 290 & 1.48 & 15.0 & 324.6 & 309.4 & 633.9 & 1.12 & 45.3 & 49.3 & 5.4 & 49.8 & 4.5 & 0.6 \\
\hline
\end{tabular}

a determined from BET method; ${ }^{b}$ determined from BJH adsorption method; ${ }^{c}$ Basic density $=$ Number of basic site/BET surface area; ${ }^{d}$ determined from EDX analysis; e determined from ICP analysis 
are shown in Figures 3 (a), (b), and (c). The morphology of all different $\mathrm{SiO}_{2}$ supports was agglomeration of particles and having the average size of particles around 5 microns. Similar SEM images were reported by Wang et al. [31]. After silver and lithium were loaded into all different $\mathrm{SiO}_{2}$ supports, it can be observed that there was only a slight change in the morphology of catalysts. The addition of silver and lithium resulted in the increase of particles coating on the silica surface. It is suggested that the loading of silver and lithium metals to the $\mathrm{SiO}_{2}$ catalysts did not change the silica structure. The EDX data of $\mathrm{AgLi} / \mathrm{SiO}_{2}-$ SPS, $\mathrm{AgLi} / \mathrm{SiO}_{2}$-MPS and $\mathrm{AgLi} / \mathrm{SiO}_{2}$-LPS catalysts are demonstrated in Figures 3 (d), (e), and (f), respectively. The location of the specific element peak, such as $\mathrm{Ag}, \mathrm{Si}$, and $\mathrm{O}$, can be detected by using EDX mapping mode. The intensity peaks of $\mathrm{Si}$ and $\mathrm{O}$ were strongly observed because $\mathrm{Si}$ and $\mathrm{O}$ are the main components of $\mathrm{SiO}_{2}$ supported catalysts. However, no any element peak of $\mathrm{Li}$ can be observed due to the very low weight loading component on $\mathrm{SiO}_{2}$ supported catalysts.

In addition, the amount of each element near the surface of catalyst granule can be determined quantitatively. The results are shown in Table 1. It can be seen that the weight percentages of silver for $\mathrm{AgLi} / \mathrm{SiO}_{2}$-SPS, $\mathrm{AgLi} / \mathrm{SiO}_{2}$-MPS, $\mathrm{AgLi} / \mathrm{SiO}_{2}$-LPS were 5.5, 5.3, and $5.4 \mathrm{wt} \%$, respectively. For all catalysts, $\mathrm{Ag}$ species were also located at the catalyst surface since the amounts of $\mathrm{Ag}$ obtained from EDX were larger than those of Ag loading (4.7 wt\% silver). In addition, it was well known that the silver concentrations at bulk (ICP analysis) were ranged between 4.3-4.6 wt\%, while $\mathrm{Li}$ contents were at $0.5-0.6 \mathrm{wt} \%$ for all $\mathrm{Ag}-\mathrm{Li}$ based catalysts. However, the element concentration from the EDX analysis, which is not a bulk (but rather surface) analytical tool, gives information down to a depth of approximately $50 \mathrm{~nm}$ from the typical external granule. To compare the silver distribution between bulk and surface analysis, the elemental concentration data are expressed in $\mathrm{Ag} / \mathrm{Si}$ ratio. The ICP results can be observed that the $\mathrm{Ag} / \mathrm{Si}$ ratio at bulk for all Ag-Li based catalysts was about 0.09. However, the ratios of $\mathrm{Ag} / \mathrm{Si}$ for $\mathrm{AgLi} / \mathrm{SiO}_{2}$-SPS, $\mathrm{AgLi} / \mathrm{SiO}_{2}$-MPS, and $\mathrm{AgLi} / \mathrm{SiO}_{2}$-LPS from EDX analysis were slightly higher than ICP analysis. This was due to the silver accumulated on the external surface of $\mathrm{SiO}_{2}$ support.
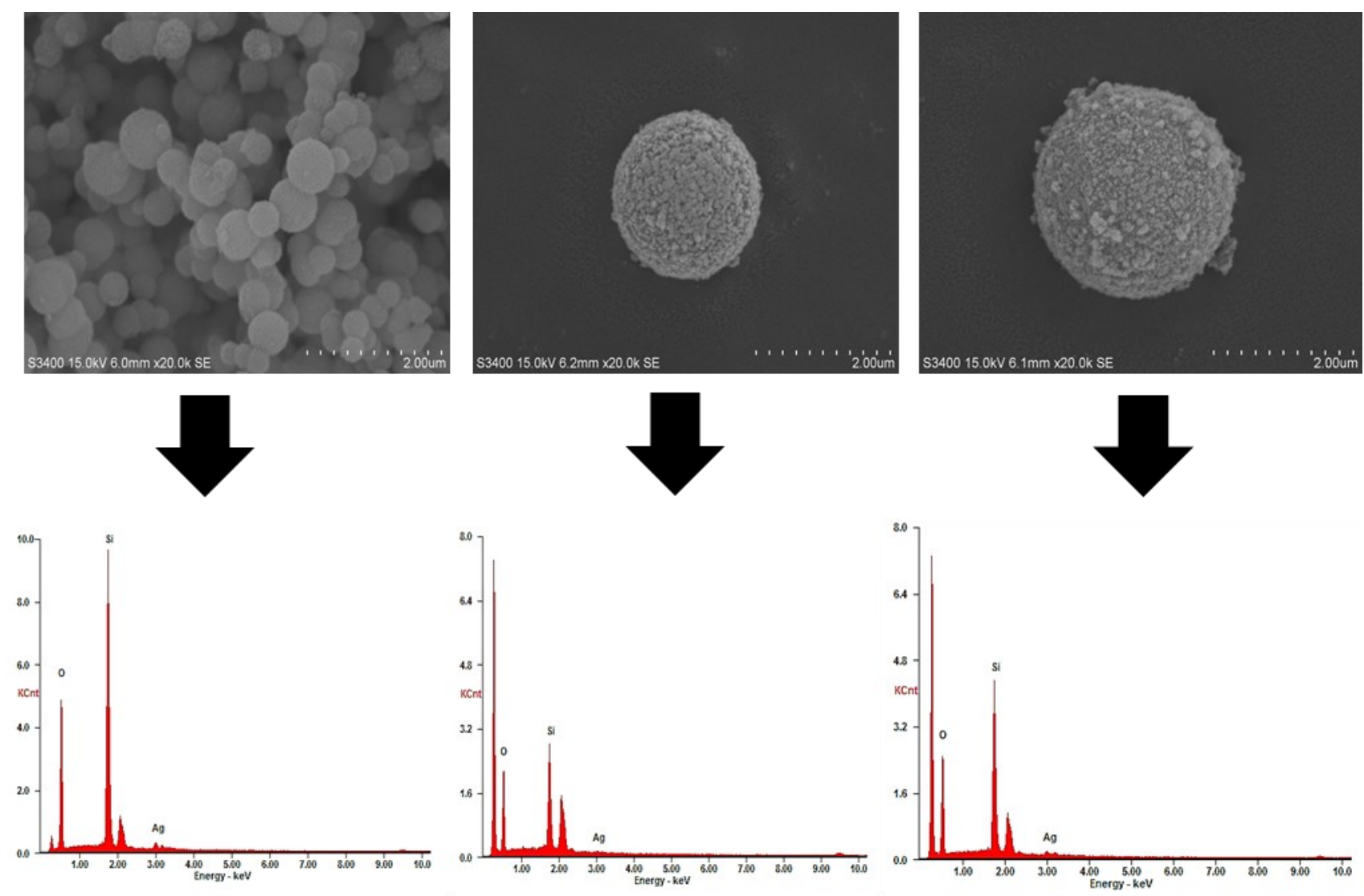

Figure 3. SEM image of all catalysts (a, b, and c); and corresponding EDX spectra of all catalysts (d, e, and $\mathrm{f}$ ) 
The optical properties of all catalysts was examined by UV-visible spectroscopy. As seen in Figure 4, the UV-visible spectra for all different $\mathrm{AgLi} / \mathrm{SiO}_{2}$ catalysts displayed the intense absorption bands around 210,310, and $430 \mathrm{~nm}$ that can be attributed to the chargetransfer from the valence band to the conduction band [19,32]. Previous studies have recognized that the absorption bands at ca. 200-250, 280-315, and 410-460 $\mathrm{nm}$ were assigned to the charge transfer bands of $\mathrm{Ag}^{+}$, small charged $\mathrm{Ag}_{\mathrm{n}}{ }^{8+}$ clusters and the metallic $\mathrm{Ag}^{0}$ particle species, respectively [20,33]. The spectra of $\mathrm{AgLi} / \mathrm{SiO}_{2}$-LPS exhibited the highest amount of $\mathrm{Ag}^{+}, \mathrm{Ag}_{\mathrm{n}}{ }^{8+}$ clusters, and metallic $\mathrm{Ag}^{0}$ species. The intensity of all catalysts decreases in the following order: $\mathrm{AgLi} / \mathrm{SiO}_{2}$-LPS $>\mathrm{AgLi} / \mathrm{SiO}_{2}-$ MPS $>\mathrm{AgLi} / \mathrm{SiO}_{2}$-SPS. This decrease in intensity resembled to the decreased catalytic performance of $\mathrm{AgLi} / \mathrm{SiO}_{2}$ catalysts. Previous works also proposed that the charge-transfer bands of $\mathrm{Ag}$ species, especially the small charged $\mathrm{Ag}_{\mathrm{n}}{ }^{8+}$ clusters may act as important state for improving the catalytic properties in alcohol oxidation reaction [34,35].

$\mathrm{H}_{2}$-TPR was performed to measure the reducibility of the catalyst samples, shown in Figure 5. In fact, the TPR profiles depend on various parameters of catalyst, such as metalsupport interaction and metal particle size distribution, resulting in different reduction behaviors [36]. The TPR profiles of $\mathrm{AgLi} / \mathrm{SiO}_{2}$ LPS and $\mathrm{AgLi} / \mathrm{SiO}_{2}$-SPS displayed the narrow peak with shoulder, while the TPR peak of $\mathrm{AgLi} / \mathrm{SiO}_{2}$-SPS was lower. However, only the narrow peak without shoulder was observed for the $\mathrm{AgLi} / \mathrm{SiO}_{2}$-MPS catalyst. The TPR peaks with shoulder can be assigned to the overlap of two steps of silver reduction. The first step was assigned to the reduction of $\mathrm{Ag}^{+}$to $\mathrm{Ag}_{\mathrm{n}}{ }^{8+}$ clus-

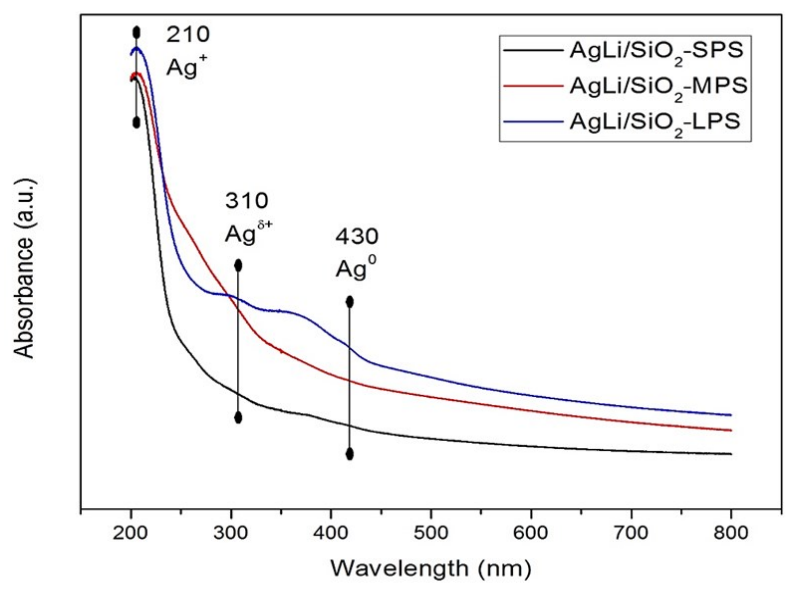

Figure 4. UV-visible spectra of all catalysts ters at the temperature range of 100 to $250{ }^{\circ} \mathrm{C}$, while second step was defined to the reduction of $\mathrm{Ag}_{\mathrm{n}}{ }^{8+}$ clusters to $\mathrm{Ag}^{0}$ at the temperature range of 250 to $330{ }^{\circ} \mathrm{C}[19,20]$. This study proposed that TPR profile displays the overlap of reduction peak from the atomic, the molecular and the lattice oxygen [37]. Thus, according to TPR profiles it was shown that the weak interaction between $\mathrm{Ag}_{\mathrm{n}}{ }^{8+}$ clusters to $\mathrm{Ag}^{0}$ was observed in the overlap of two step reduction for the $\mathrm{AgLi} / \mathrm{SiO}_{2}$-SPS and $\mathrm{AgLi} / \mathrm{SiO}_{2}$-LPS catalysts. It may lead to improve catalytic performance in dehydrogenation of ethanol as reported elsewhere [37-41] for silver-supported catalysts.

The basic properties of catalysts are crucial to determine the catalytic activity and product distribution by oxidative dehydrogenation of alcohols. Hence, the carbon dioxide temperature-programmed desorption $\left(\mathrm{CO}_{2}\right.$-TPD) was performed. As seen in Figure 6, it can be observed that the $\mathrm{CO}_{2}$-TPD profiles were

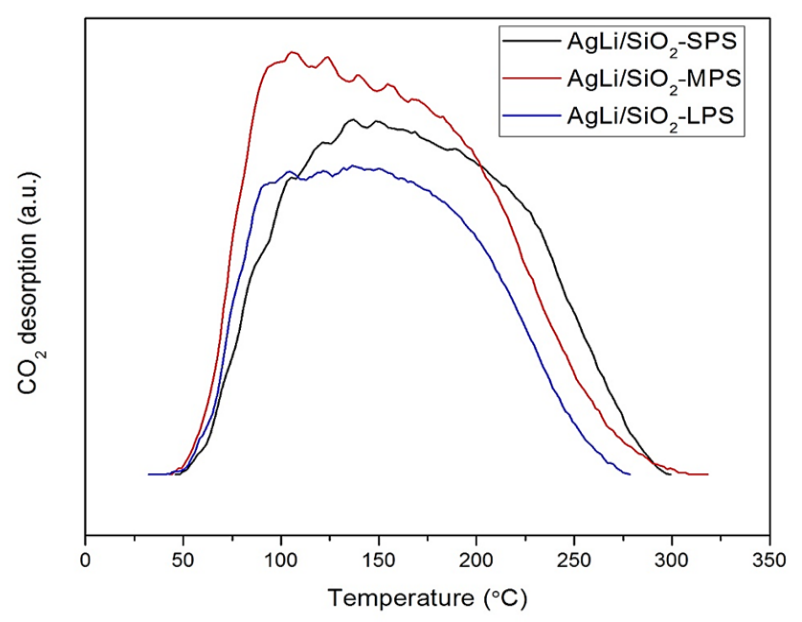

Figure 6. $\mathrm{CO}_{2}$-TPD profile of all catalysts

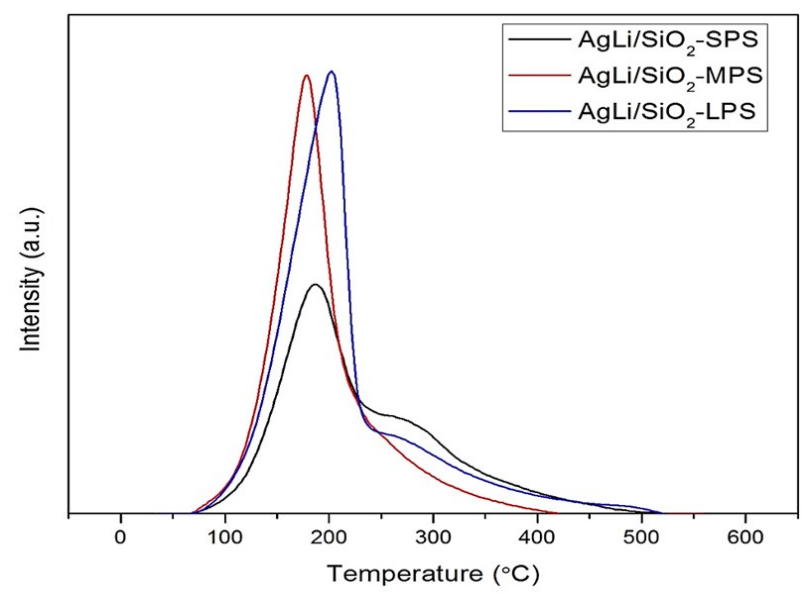

Figure 5. $\mathrm{H}_{2}$-TPR profile of all catalysts 
presented at the temperature from ca. 50-300 ${ }^{\circ} \mathrm{C}$. The $\mathrm{CO}_{2}$-TPD profiles occur at low desorption temperature between $50-150{ }^{\circ} \mathrm{C}$, which is referred to $\mathrm{CO}_{2}$ with weakly $\mathrm{OH}$ - groups adsorbed on the catalyst surface [42]. Whereas, the medium $\left(150{ }^{\circ} \mathrm{C}\right)$ and high $\left(>250{ }^{\circ} \mathrm{C}\right)$ desorption peak can be ascribed to the formation of different carbonate species whose adsorption is stronger than carbon dioxide $[43,44]$. The results show that all different $\mathrm{AgLi} / \mathrm{SiO}_{2}$ catalysts mostly contained the weak basic sites. By integrating the area under desorption peaks, the amount of $\mathrm{CO}_{2}$ desorbed, especially related to the amounts of weak basic sites from the catalysts decreases according to the following order: $\mathrm{AgLi} / \mathrm{SiO}_{2}$-MPS (443.0 umole $\mathrm{CO}_{2} / \mathrm{g}$ ) > $\mathrm{AgLi} / \mathrm{SiO}_{2}$-SPS (416.5 umole $\left.\mathrm{CO}_{2} / \mathrm{g}\right)>$ $\mathrm{AgLi} / \mathrm{SiO}_{2}$-LPS (324.6 $\mu$ mole $\mathrm{CO}_{2} / \mathrm{g}$ ) (see Table 1). Many researchers $[19,29,45]$ have convinced that the weak basic sites critically participate for ethanol oxidative dehydrogenation. In spite of the decrease of weak basic sites, these cata-

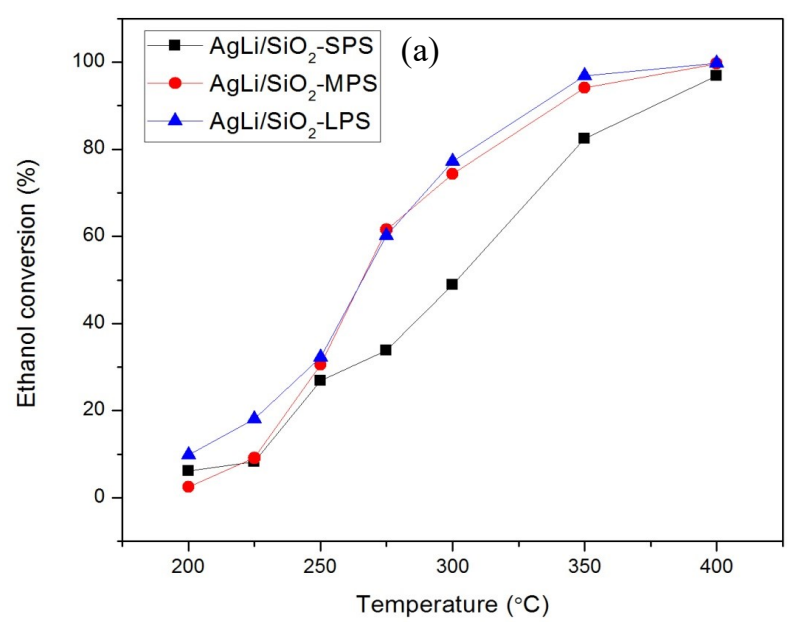

lysts show high values of basic density expressed as $\mu$ moles of $\mathrm{CO}_{2}$ per surface unit (Table 1), due to their low specific BET surface areas. Zhan et al. [46] suggested that the increase of the basic density may be the reason for improving the catalytic performance. The $\mathrm{CO}_{2}$-TPD results of all catalysts apparently agree with their catalytic activity.

\subsection{Reaction Test}

3.2.1 Ethanol oxidative dehydrogenation reaction

The catalytic activity of all different $\mathrm{AgLi} / \mathrm{SiO}_{2}$ catalysts was considered in the effect of addition of oxygen (air) as a co-feed reactant or oxidative dehydrogenation of ethanol as a function of reaction temperature. The ethanol oxidative dehydrogenation is apparently significant between $200{ }^{\circ} \mathrm{C}$ to $400{ }^{\circ} \mathrm{C}$ as shown in Figure 7. For all catalysts, the ethanol conversion increased when reaction temperature is increased, reaching ca. $77.2 \%$ for
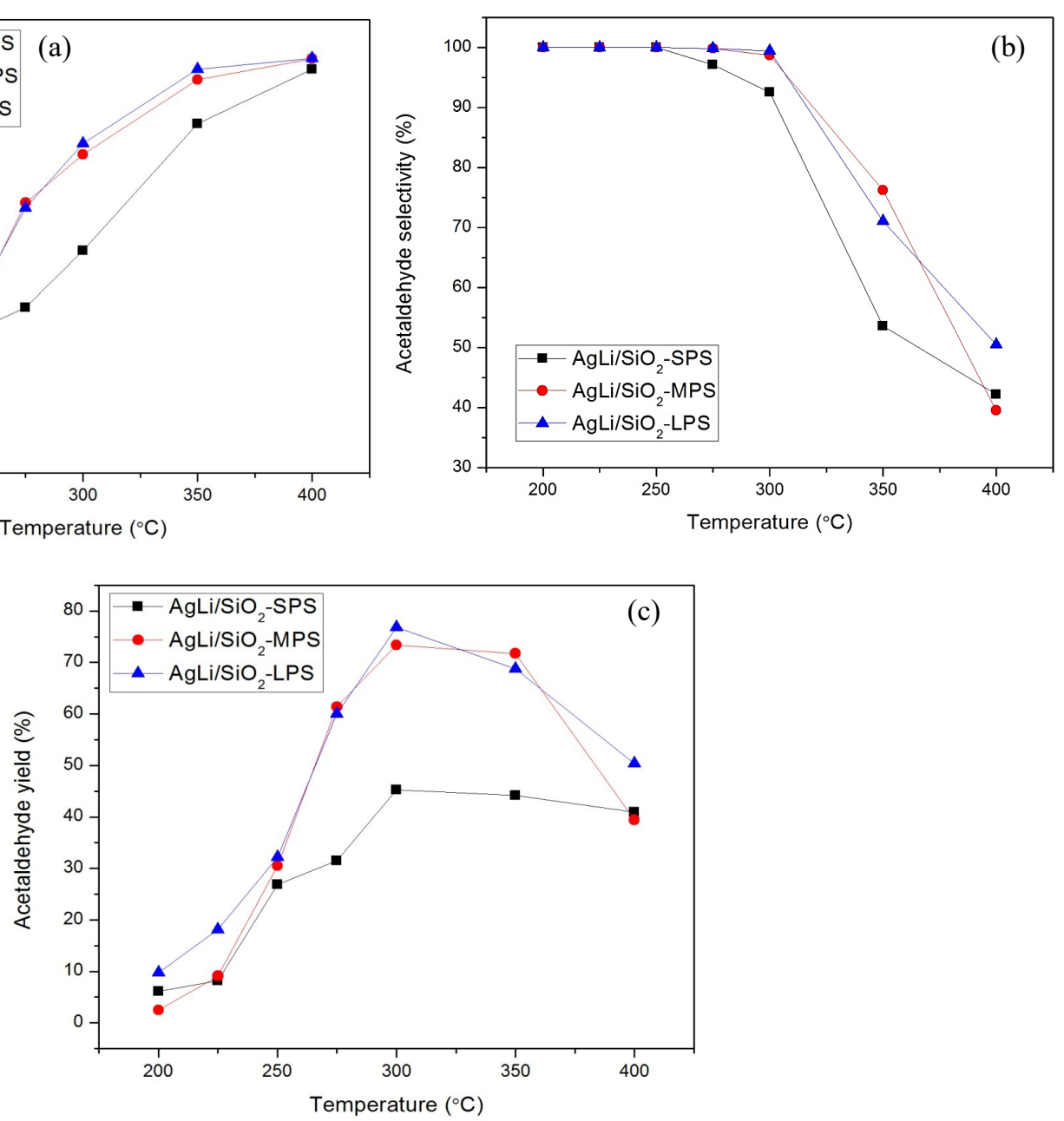

Figure 7. Ethanol conversion (a), acetaldehyde selectivity, (b) and acetaldehyde yield, (c) of all catalysts in ethanol oxidative dehydrogenation. Reaction condition: $0.05 \mathrm{~g}$ catalyst, Ethanol flowrate $=1.45$ $\mathrm{mL} / \mathrm{h}$, at atmosphere pressure, WHSV $=22.9\left(\mathrm{~g}_{\text {ethanol. }} \mathrm{g}_{\text {cat }}{ }^{-1}\right) \cdot \mathrm{h}^{-1}$. 
$\mathrm{AgLi} / \mathrm{SiO}_{2}$-LPS at $300{ }^{\circ} \mathrm{C}$ and slightly increases at the temperature range of $350{ }^{\circ} \mathrm{C}(96.8 \%)$ to $400{ }^{\circ} \mathrm{C}(99.8 \%)$ under steady-state conditions as shown in Figure 7(a). The ethanol conversion of all catalysts can be arranged in the following order: $\mathrm{AgLi} / \mathrm{SiO}_{2}$-LPS > $\mathrm{AgLi} / \mathrm{SiO}_{2}$-MPS > $\mathrm{AgLi} / \mathrm{SiO}_{2}$-SPS. These results agree well with the result from UV-visible spectroscopy. The amounts of small charged $\mathrm{Ag}_{\mathrm{n}}{ }^{8+}$ clusters and $\mathrm{Ag}^{0}$ played a relevant role to improve the catalytic activity. Based on some works as reported by Pestryakov et al. [47], we probably proposed the hypothesis that $\mathrm{Ag}_{\mathrm{n}}{ }^{8+}$ cluster and $\mathrm{Ag}^{0}$ are active sites of $\mathrm{SiO}_{2}$ supported catalyst for ethanol oxidative dehydrogenation. Moreover, the tendency of reducibility obtained from $\mathrm{H}_{2}$-TPR technique was similar as the results obtained from UV-visible spectroscopy.

The selectivity of acetaldehyde over all different $\mathrm{AgLi} / \mathrm{SiO}_{2}$ catalysts is shown in Figure 7(b). The results represented the closely complete acetaldehyde selectivity (99-100\%) produced from ethanol oxidative dehydrogenation with the temperature up to ca. 200 to $275{ }^{\circ} \mathrm{C}$. The minor undesired product was diethyl ether (0.3-2.7\%) and ethylene (0.2-6.3\%), which is related to some remaining acid sites on the catalyst surface. In particular, the $\mathrm{AgLi} / \mathrm{SiO}_{2}$-LPS catalyst still exhibits outstanding catalytic activity regarding the acetaldehyde selectivity with values almost ca. $100 \%$ between $275-300$ ${ }^{\circ} \mathrm{C}$, likely due to their highest amount of weak basic density $\left(1.12 \mu \mathrm{mol} / \mathrm{m}^{2}\right.$, see Table 1$)$. Additionally, with higher basic density and shorter distance between two basic sites (Ag-Li), it is advantage to increase the opportunity of the reactant to be adsorbed and rapidly catalyzed to produce the chemical product, especially acetaldehyde selectivity at suitable reaction temperature [19]. However, the acetaldehyde selectivity apparently decreased to $39.5-50.5 \%$ when the increased reaction temperature in the range of ca. $350-400{ }^{\circ} \mathrm{C}$. In fact, the acetaldehyde selectivity of all catalysts was found to decrease along with increased amounts of carbon oxides $\left(\mathrm{CO}\right.$ and $\mathrm{CO}_{2}$ ) due to further oxidation of acetaldehyde with the presence of oxygen $\left(\mathrm{O}_{2}\right)$ as summarized in Supplementary Table S1.

The yield of the products was calculated by multiplying the conversion of ethanol by the selectivity of the product. The acetaldehyde yield is shown in Figure 7 (c). At $300{ }^{\circ} \mathrm{C}$, acetaldehyde yield was found to be in the order of $\mathrm{AgLi} / \mathrm{SiO}_{2}$-LPS (76.8\%) $>\mathrm{AgLi} / \mathrm{SiO}_{2}-\mathrm{MPS}$ $(73.4 \%)>\mathrm{AgLi} / \mathrm{SiO}_{2}-\mathrm{SPS}$ (45.3\%). From all catalysts, $\mathrm{AgLi} / \mathrm{SiO}_{2}$-LPS represents an excellent result that gives the highest value of acetalde- hyde yield reached $76.8 \%$ at $300{ }^{\circ} \mathrm{C}$, which is promising catalyst for oxidative dehydrogenation of ethanol to acetaldehyde. When increasing the reaction temperature up to 400 ${ }^{\circ} \mathrm{C}$, the acetaldehyde yield decreased due to the formation of mainly carbon oxides at high reaction temperature. Based on the characterization data, we conclude that the active sites on the catalyst surface such as the interaction between $\mathrm{Ag}$ oxide species and $\mathrm{SiO}_{2}$ nanoparticle, $\mathrm{Ag}_{\mathrm{n}}{ }^{8+}$ clusters and $\mathrm{Ag}^{0}$, weak basic density and other parameters are crucial. According to our previous works $[19,20]$, we confirmed that the redox properties $\left(\mathrm{Ag}_{\mathrm{n}}{ }^{8+}\right.$ and $\left.\mathrm{Ag}^{0}\right)$ can strongly affect in ethanol oxidative dehydrogenation. Besides, the particle of $\mathrm{SiO}_{2}$ supports had a little effect on the identity of the primary selective oxidation product, acetaldehyde. It is generally accepted in the literature $[48,49]$ that a larger particle $>1,340 \mathrm{~nm}(1.34 \mu \mathrm{m})$, leading to a higher apparent reaction rate, as reflected by the higher conversion and selectivity. It thus appears that the combination of different characterization techniques can elucidate the change in catalytic performance of all different $\mathrm{AgLi} / \mathrm{SiO}_{2}$ catalysts. Consequently, it can be concluded that the small charged $\mathrm{Ag}_{\mathrm{n}}{ }^{8+}$ clusters and $\mathrm{Ag}^{0}$ as well as the weak basic density on the catalyst surface play a positive synergetic effect for high catalytic performance of this reaction. Nevertheless, some significant challenges and greater achievements remain to be solved in the near future.

\section{Conclusions}

In this study, the results of $\mathrm{AgLi} / \mathrm{SiO}_{2}$ catalysts containing different types of silica supports (SPS, MPS, and LPS) obtained by incipient wetness co-impregnation method were considered for ethanol oxidative dehydrogenation in the reaction temperature ranging from 200 to $400{ }^{\circ} \mathrm{C}$. A correlation between the interfacial $\mathrm{Ag}-\mathrm{Li}$ interaction and the enhanced catalytic performance in ethanol oxidative dehydrogenation was found by physicochemical properties including reduction behaviors and basicity of all different $\mathrm{AgLi} / \mathrm{SiO}_{2}$ catalysts. Among the various candidates tested during this study, the $\mathrm{AgLi} / \mathrm{SiO}_{2}$-LPS catalyst presented the highest catalytic performance, with an acetaldehyde yield of $76.8 \%$ at $300{ }^{\circ} \mathrm{C}$. Detailed characterization of the catalysts revealed that the dispersion of active components, the interaction between active components and their supports, the textural properties of catalysts and reducibility played significant roles in ethanol oxidative dehydrogenation reaction. Especially, the 
cooperation of redox properties $\left(\mathrm{Ag}_{\mathrm{n}}{ }^{8+}\right.$ cluster and $\left.\mathrm{Ag}^{0}\right)$ as well as weak basic density is probable the reason for high catalytic performance of this reaction and needs additional in situ studies for confirmation.

\section{Acknowledgements}

This research is funded by Chulalongkorn University and CAT-REAC industrial project.

\section{References}

[1] Sun, J., Wang, Y. (2014). Recent advances in catalytic conversion of ethanol to chemicals, ACS Catal., 4, 1078-1090.

[2] Angelici, C., Weckhuysen, B.M., Bruijnincx, P. (2013). Chemocatalytic conversion of ethanol into butadiene and other bulk chemicals, Chem SusChem., 6, 1595-1614.

[3] Shan, J., Liu, J., Li, M., Lustig, S., Lee, S., Flytzani-Stephanopoulos, M. (2018). NiCu single atom alloys catalyze the $\mathrm{CH}$ bond activation in the selective non-oxidative ethanol dehydrogenation reaction, Appl. Catal. B., $226,534-543$.

[4] Shan, J., Janvelyan, N., Li, H., Liu, J., Egle, T.M., Ye, J., Biener, M.M., Biener, J., Friend, C.M., Stephanopoulos, M.F. (2017). Selective non-oxidative dehydrogenation of ethanol to acetaldehyde and hydrogen on highly dilute NiCu alloys, Appl. Catal. B., 205, 541-550.

[5] Rodriguez-Gomez, A., Holgado, J. P., Caballero, A. (2017). Cobalt carbide identified as catalytic site for the dehydrogenation of ethanol to acetaldehyde, ACS Catal., 7, 5243-5247.

[6] Zeng, G., Chen, T., He, L., Pinnau, I., Lai, Z., Huang, K.W. (2012). A green approach to ethyl acetate: quantitative conversion of ethanol through direct dehydrogenation in a $\mathrm{Pd}-$ $\mathrm{Ag}$ membrane reactor, Chem. Eur. J., 18, 15940-15943.

[7] Otsuka, K., Uragami, Y., Hatano, M. (1992). The partial oxidation of ethane to acetaldehyde, Catal. Today, 13, 667-672.

[8] Ponomarev, D.A., Shevchenko, S.M. (2007). Hydration of acetylene: A 125th anniversary, J. Chem. Educ., 84, 1725-1726.

[9] Fujimoto, K., Takeda, H., Kunugi, T. (1974). Catalytic oxidation of ethylene to acetaldehyde. Palladium chloride-active charcoal catalyst, Ind. Eng. Chem. Prod. Res. Dev., 13, 237 242.

[10] Caro, C., Thirunavukkarasu, K., Anilkumar, M., Shiju, N., Rothenberg, G. (2012). Selective Autooxidation of Ethanol over Titania-Supported Molybdenum Oxide Catalysts: Structure and Reactivity, Adv. Synth. Catal., 354, 1327-1336.
[11] Gomez, M.F., Arrua, L.A., Abello, M.C. (1997). Kinetic study of partial oxidation of ethanol over V-MgO catalyst, Ind. Eng. Chem. Res., 36, 3468-3472.

[12] Tu, Y.-J., Chen, Y.-W. (2001). Effects of alkali metal oxide additives on $\mathrm{Cu} / \mathrm{SiO}_{2}$ catalyst in the dehydrogenation of ethanol, Ind. Eng. Chem. Res., 40, 5889-5893.

[13] Quaranta, N., Soria, J., Corberan, V.C., Fierro, J. (1997). Selective Oxidation of Ethanol to Acetaldehyde on $\mathrm{V}_{2} \mathrm{O}_{5} / \mathrm{TiO}_{2} / \mathrm{SiO}_{2}$ Catalysts, J. Catal., 171, 1-13.

[14] Glinrun, T., Mekasuwandumrong, O., Panpranot, J., Chaisuk, C., Praserthdam, P. (2010). Improvement of propane oxidation activity over $\mathrm{Pt} / \mathrm{Al}_{2} \mathrm{O}_{3}$ by the use of MIXED Yand $\mathrm{X}-\mathrm{Al}_{2} \mathrm{O}_{3}$ supports, React. Kinet. Mech. Catal., 100, 441-448.

[15] Meephoka, C., Chaisuk, C., Samparnpiboon, P., Praserthdam, P. (2008). Effect of phase composition between nano $\mathrm{Y}$-and $\mathrm{X}-\mathrm{Al}_{2} \mathrm{O}_{3}$ on $\mathrm{Pt} / \mathrm{Al}_{2} \mathrm{O}_{3}$ catalyst in $\mathrm{CO}$ oxidation, Catal. Commun., 9, 546-550.

[16] Sushkevich, V.L., Ivanova, I.I., Ordomsky, V.V., Taarning, E. (2014). Design of a Metal-Promoted Oxide Catalyst for the Selective Synthesis of Butadiene from Ethanol, ChemSusChem, 7, 2527-2536.

[17] Grabchenko, M.V., Mamontov, G.V., Zaikovskii, V.I., La Parola, V., Liotta, L.F., Vodyankina, O. (2019). Design of $\mathrm{Ag}-\mathrm{CeO}_{2} / \mathrm{SiO}_{2}$ catalyst for oxidative dehydrogenation of ethanol: Control of $\mathrm{Ag}-\mathrm{CeO}_{2}$ interfacial interaction, Catal. Today, 333, 2-9.

[18] Magaev, O.V., Knyazev, A.S., Vodyankina, O.V., Mamontov, G. (2013). Influence of phosphate addition on activity of $\mathrm{Ag}$ and $\mathrm{Cu}$ catalysts for partial oxidation of alcohols, Catal. Today., 203, 122-126.

[19] Autthanit, C., Chatkaew, W., Praserthdam, P., Jongsomjit, B. (2020). Effect of different phase composition in titania on catalytic behaviors of $\mathrm{AgLi} / \mathrm{TiO}_{2}$ catalysts via ethanol dehydrogenation. J. Environ. Chem. Eng., 8, 103547.

[20] Janlamool, J., Jongsomjit, B. (2015). Oxidative dehydrogenation of ethanol over $\mathrm{AgLi}-$ $\mathrm{Al}_{2} \mathrm{O}_{3}$ catalysts containing different phases of alumina, Catal. Commun., 70, 49-52.

[21] Krutpijit, C., Tian, W., Jongsomjit, B., Pjontek, D., Herrera, J.E. (2020). Lithium promotion in ethanol oxidative dehydrogenation over Al-modified Ag/Montmorillonite clays, Mol. Catal., 483, 110717.

[22] Kerdnoi, P., Autthanit, C., Chitpong, N., Jongsomjit, B. (2020). Catalytic Dehydration of Ethanol over $\mathrm{W} / \mathrm{TiO}_{2}$ Catalysts Having Dif- 
ferent Phases of Titania Support, Bull. Chem. React. Eng. Catal., 15, 96-103.

[23] Kamsuwan, T., Praserthdam, P., Jongsomjit, B. (2020). Tuning of catalytic behaviors in ethanol dehydration with oxygen cofeeding over Pd-HBZ catalyst for ethylene production at low temperature, Catal. Commun., 137, 105941.

[24] Huang, X., Men, Y., Wang, J., An, W., Wang, Y. (2017). Highly active and selective binary $\mathrm{MgO}-\mathrm{SiO}_{2}$ catalysts for the production of 1, 3butadiene from ethanol, Catal. Sci. Technol., 7, 168-180.

[25] Akhade, S.A., Winkelman, A., Dagle, V.L., Kovarik, L., Yuk, S.F., Lee, M.-S., Zhang, J., Padmaperuma, A.B., Dagle, R.A., Glezakou, V.-A., Wang, Y., Rousseau, R. (2020). Influence of $\mathrm{Ag}$ metal dispersion on the thermal conversion of ethanol to butadiene over Ag$\mathrm{ZrO}_{2} / \mathrm{SiO}_{2}$ catalysts, J. Catal., 386, 30-38.

[26] Chanchuey, T., Autthanit, C., Jongsomjit, B. (2016). Effect of Mo-doped mesoporous Al-SSP catalysts for the catalytic dehydration of ethanol to ethylene, J. Chem., 2016, Article ID 9672408 .

[27] Mamontov, G., Grabchenko, M., Sobolev, V., Zaikovskii, V., Vodyankina, O. (2016). Ethanol dehydrogenation over $\mathrm{Ag}-\mathrm{CeO}_{2} / \mathrm{SiO}_{2}$ catalyst: role of $\mathrm{Ag}-\mathrm{CeO}_{2}$ interface, Appl. Catal. A: Gen., 528, 161-167.

[28] Fuchigami, K., Taguchi, Y., Tanaka, M. (2008). Synthesis of spherical silica particles by sol-gel method and application, Polym. Adv. Technol., 19, 977-983.

[29] Autthanit, C., Praserthdam, P., Jongsomjit, B. (2018). Oxidative and non-oxidative dehydrogenation of ethanol to acetaldehyde over different $\mathrm{VO}_{\mathrm{x}} / \mathrm{SBA}-15$ catalysts, J. Environ. Chem. Eng., 6, 6516-6529.

[30] Zhang, G., Xu, Y., Xu, D., Wang, D., Xue, Y., $\mathrm{Su}, \mathrm{W}$. (2008). Pressure-induced crystallization of amorphous $\mathrm{SiO}_{2}$ with silicon-hydroxy group and the quick synthesis of coesite under lower temperature, High. Press. Res., 28, 641650 .

[31] Wang, H., Chen, Z., Chen, D., Yu, Q., Yang, W., Zhou, J., Wu, S. (2019). Facile, templatefree synthesis of macroporous $\mathrm{SiO}_{2}$ as catalyst support towards highly enhanced catalytic performance for soot combustion, Chem. Eng. J., 375, 121958.

[32] Wu, J.C.-S., Chen, C.-H. (2004). A visiblelight response vanadium-doped titania nanocatalyst by sol-gel method, J. Photochem. Photobiol. A., 163, 509-515.

[33] Pestryakov, A.N., Davydov, A. (1995). Study of supported silver states by the method of electron spectroscopy of diffuse reflectance, $J$. Electron Spectrosc. Relat. Phenom., 74, 195199.

[34] Pestryakov, A.N., Davydov, A. (1994). Active electronic states of silver catalysts for methanol selective oxidation, Appl. Catal. A, 120, 7 15.

[35] Pestryakov, A.N. (1996). Modification of silver catalysts for oxidation of methanol to formaldehyde, Catal. Today, 28, 239-244.

[36] Pinna, F., Fantinel, T., Strukul, G., Benedetti, A., Pernicone, N. (1997). TPR and XRD study of ammonia synthesis catalysts, Appl. Catal., A, 149, 341-351.

[37] Kim, Y.-C., Park, N.-C., Shin, J.-S., Lee, S. R., Lee, Y.J., Moon, D. (2003). Partial oxidation of ethylene to ethylene oxide over nanosized Ag/a- $\mathrm{Al}_{2} \mathrm{O}_{3}$ catalysts, Catal. Today., 87, 153162.

[38] Grabchenko, M., Mamontov, G., Zaikovskii, V., La Parola, V., Liotta, L., Vodyankina, O. (2018). Design of $\mathrm{Ag}-\mathrm{CeO}_{2} / \mathrm{SiO}_{2}$ catalyst for oxidative dehydrogenation of ethanol: Control of $\mathrm{Ag}-\mathrm{CeO}_{2}$ interfacial interaction, Catal. Today, 333, 2-9.

[39] Deng, X., Li, M., Zhang, J., Hu, X., Zheng, J., Zhang, N., Chen, B. (2017). Constructing nano-structure on silver/ceria-zirconia towards highly active and stable catalyst for soot oxidation, Chem. Eng. J., 313, 544-555.

[40] Aneggi, E., Llorca, J., de Leitenburg, C., Dolcetti, G., Trovarelli, A. (2009). Soot combustion over silver-supported catalysts. Appl. Catal., B, 91, 489-498.

[41] Shimizu, K.-i., Kawachi, H., Satsuma, A. (2010). Study of active sites and mechanism for soot oxidation by silver-loaded ceria catalyst, Appl. Catal., B, 96, 169-175.

[42] Shi, R., Wang, F., Mu, X., Li, Y., Huang, X., Shen, W. (2009). MgO-supported $\mathrm{Cu}$ nanoparticles for efficient transfer dehydrogenation of primary aliphatic alcohols. Catal. Commun., 11, 306-309.

[43] Zhang, X., Wan, H.-l., Weng, W.-z., Yi, X.-d. (2003). Effect of Ag promoter on redox properties and catalytic performance of Ag-Mo-PO catalysts for oxidative dehydrogenation of propane, Appl. Surf. Sci., 220, 117-124.

[44] Bahruji, H., Bowker, M., Brookes, C., Davies, P.R., Wawata, I. (2013). The adsorption and reaction of alcohols on $\mathrm{TiO}_{2}$ and $\mathrm{Pd} / \mathrm{TiO}_{2}$ catalysts, Appl. Catal., A, 454, 66-73.

[45] Pinthong, P., Praserthdam, P., Jongsomjit, B. (2020). Oxidative dehydrogenation of ethanol over $\mathrm{Cu} / \mathrm{Mg}-\mathrm{Al}$ catalyst derived from hydrotalcite: effect of ethanol concentration and reduction conditions, J. Zhejiang. Univ-Sc. A, 21, 218-228. 
[46] Zhan, N., Hu, Y., Li, H., Yu, D., Han, Y., Huang, H. (2010). Lanthanum-phosphorous modified HZSM-5 catalysts in dehydration of ethanol to ethylene: A comparative analysis, Catal. Commun., 11, 633-637.

[47] Pestryakov, A.N., Davydov, A. (1994). Active electronic states of silver catalysts for methanol selective oxidation, Appl. Catal., A, 120, 715 .
[48] Burattin, P., Che, M., Louis, C. (1999). Metal particle size in $\mathrm{Ni} / \mathrm{SiO}_{2}$ materials prepared by deposition-precipitation: Influence of the nature of the Ni (II) phase and of its interaction with the support, J. Phys. Chem. B, 103, 6171-6178.

[49] Ye, G., Sun, Y., Guo, Z., Zhu, K., Liu, H., Zhou, X., Coppens, M.-O. (2018). Effects of zeolite particle size and internal grain boundaries on Pt/Beta catalyzed isomerization of $\mathrm{n}$ pentane, Journal of Catalysis., 360, 152-159 